\title{
LXI. On the chemical nature of a wax from China
}

\section{Benjamin Collins Brodie Esq.}

To cite this article: Benjamin Collins Brodie Esq. (1848) LXI. On the chemical nature of a wax from China, Philosophical Magazine Series 3, 33:223, 378-391, DOI:

10.1080/14786444808646124

To link to this article: http://dx.doi.org/10.1080/14786444808646124

$$
\text { 曲 Published online: } 30 \text { Apr } 2009 .
$$

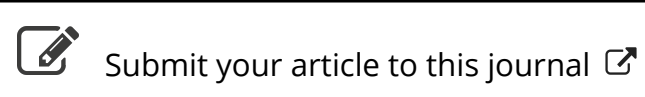

Џلl Article views: 2

Q View related articles $\sqsubset$ 
height. The appearance could no longer be compared to that of a fan but to that of a dome of fire; the unillumined portion of the horizon became confined to atiout one-fourth part of the circle, extending more or less between S.S.W. and E.: $\gamma$ Pegasi became enveloped in the light which shot southwards from the summit, passing several degrees below Saturn, so that in the S.E. not more than a space of about $30^{\circ}$ in altitude remained dark, while all the rest of the heavens seemed on fire. The summit of the dome presented several remarkable changes of appearance: at one time the rays met as at a point, with great regularity; at another there were seen great irregular masses of light gathered round it, and at another there was a distinct circle round the centre, which was dark. As the evening advanced, this crown changed its position among the stars to a considerable extent, retaining however the same altitude and azimuth as the stars moved westward. After $9^{\mathrm{h}} 30^{\mathrm{m}}$ P.M. the grandeur of the scene diminished, and at $10^{\mathrm{h}} 30^{\mathrm{m}}$ P.M. the crimson colour had disappeared; still the streamers continued with great vigour till October 19, at $1^{\mathrm{h}} 30^{\mathrm{m}}$ A.M., at which time the observations were discontinued.

The altitude and azimuth of the corona were determined from the spherical triangle S P Y, in which S P represents the north-polar distance, and S P Y the hourangle of $\alpha$ Andromedæ at $9^{\text {h P.M. }}$.

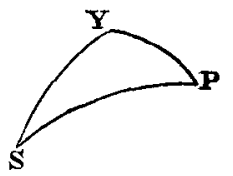

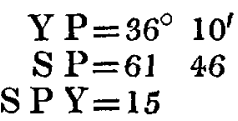

From this the zenith distance of the corona appears to have been about $18^{\circ}$ south, and its azimuth to have been about $41^{\circ}$ east.

On the 19th and 20th there were also slight exhibitions of aurora borealis. On these days the magnets at Greenwich Observatory were affected, as I learn both from Mr. Glaisher and from the Registrar-General's Report for the week ending October 21st.

\section{On the Chemical Nature of a Wax from China.} By Benjamin Collins Brodie, Esq.*

THE wax which is the subject of the following investigation, 1 is a substance which was imported into this country from China as an article of commerce. Its appearance closely resembles that of spermaceti. It is, like spermaceti, white and, in large masses, highly crystalline, but differs from it by being

* From the Philosophical 'Transactions, part i.; having been received by the Royal Society March 30, and read May 11, 1848. 
harder, more brittle, and of a more fibrous character of crystallization. The melting-point of the wax is about $83^{\circ} \mathrm{C}$. It is but very slightly soluble in either alcohol or æther, but dissolves with great facility in naphtha, out of which fluid it may be crystallized. This substance is generally spoken of as a vegetable wax: on looking however into such facts as I can gather which throw any light on its origin, it seems more than probable that, like bees'-wax, it is the secretion of an insect. Sir George Staunton, in his Embassy to China*, gives an account of a wax of insect origin, which there formed an article of trade, and in his work may be seen a drawing of the insect and of the tree on which the insect lives. Other writers on China give a similar account. In the Comptes Rendus for $1840+$ is a paper by M. Stanislas Julien, who gives an account of this tree wax, and states it to be the work of an insect: where may be found also a great number of extracts from Chinese writers on agriculture, giving an account of the insect itself and of the trees suitable for its food; one of these trees is the Rhus succedaneum. This same gentlernan, M. Stanislas Julien, gave to M. Lewy, who was engaged in an investigation on these wax substances, a specimen of the wax from this very plant, which is therefore in all probability this insect-wax. The melting-point, the appearance and the analysis of this wax, as given by M. Lewy, agree so exactly with those of the wax which I have examined, that I cannot but believe them to be the same chemical substance, and that this wax also is of insect origin.

The existence of any other wax-making insect, such as this Coccus ceriferus, besides the bee, is a point of considerable interest in relation to the question as to the origin of the wax in that insect, and the possibility of the chemical transformations by which it is produced.

The Chinese wax, as it appears in commerce, is a substance nearly in a state of chemical purity. By alcohol small portions of a greasy matter may be separated from it, and on distillation it affords traces of acroleine, which is not a product of the distillation of the pure wax. The impurities however are unimportant.

I have spoken of this substance as a wax; and in truth, although to the eye it more nearly resembles spermaceti or stearine than ordinary bees'-wax, the substance, nevertheless,

* Vol. i. p. 352, edition 1797.

+ Vol. x. p. 619. The title is "Nouveause renseignements sur la cire d'arbre, et sur les insecies qui la produisent." See also in the same volume, M. Virey, Sur les insecies qui produisent la substance appelée par les Chinois, "Cire d'arbre." 
which, even in appearance, it more nearly resembles than any other, is the purified cerine, that is, that cerotic acid of which, mixed with certain other waxy matter, in a former paper, I have shown the bees'-wax to consist. The accurate investigation of the chemical nature of the Chinese wax has brought to light certain curious chemical relations which exist between these bodies, and led to the discovery of the alcohol of cerotic acid.

\section{Cerotine.}

Chinese wax may be boiled for a long time either with dilute or with concentrated potash with hardly any signs of saponification. If, however, it be melted with the hydrate of potash, it is readily decomposed. This decomposition is best effected in an iron basin over a large gas flame or gentle fire. The mass, after the action, is soluble in boiling water, giving a milky solution. From this solution two substances may be procured; an acid which may be combined with baryta by precipitation of the soap with chloride of barium; and a waxsubstance of another nature which is obtained by washing out the baryta salt with any suitable solvent, such as alcohol, æether, or naphtha. The soap, after precipitation by chloride of barium, becomes perfectly clear, and, to obtain the wax-substance which is not combined with the baryta, the baryta salt is first to be separated by filtration from the fluid, then dried and pulverized. It is convenient to effect, at first, a partial separation of the salt from the other matter by washing it out with a large quantity of boiling alcohol, and filtering the solution hot through linen. After this operation has been two or three times repeated, the substance, which passes through the filter, is to be redissolved in the same alcohol and the solutions filtered, in a similar manner, through paper, so as to separate the small portions of the baryta salt which unavoidably pass through the linen. The solution is much facilitated by the addition of a small quantity of naphtha to the alcohol. If the substance be purified by crystallization out of æther and absolute alcohol, its melting-point will be raised to $79^{\circ} \mathrm{C}$. Previous to analysis the substance is to be dissolved in absolute alcohol and æther, and the solution filtered. This is a necessary precaution, as the naphtha dissolves traces of the baryta salt. The substance was analysed.

I. 0.258 grm. gave $0.7725 \mathrm{CO}_{2}$ and $0.327 \mathrm{HO}$.

II. The numbers have been mislaid.

III. $0.2602 \mathrm{grm}$, another preparation, gave $0.7785 \mathrm{CO}_{\mathcal{q}}$ and $0.334 \mathrm{HO}$, which give in 100 parts,- 
I. II. III.

\begin{tabular}{|c|c|c|c|}
\hline $\begin{array}{l}\text { Carbon - } \\
\text { Hydrogen } \\
\text { Oxygen . }\end{array}$ & $\begin{array}{r}81 \cdot 55 \\
14 \cdot 08 \\
4 \cdot 37\end{array}$ & $\begin{array}{r}81 \cdot 76 \\
14.25 \\
3.99\end{array}$ & $\begin{array}{r}81 \cdot 59 \\
14.26 \\
4 \cdot 15\end{array}$ \\
\hline & $100 \cdot 00$ & $100 \cdot 00$ & $100 \cdot 00$ \\
\hline
\end{tabular}

These numbers give the formula $\mathrm{C}_{54} \mathrm{H}_{56} \mathrm{O}_{2}$.

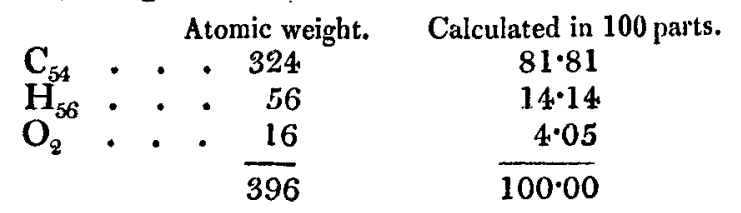

This is the formula of an alcohol. Other experiments decided that this was in truth the class of bodies to which this substance belonged, and led me to adopt the particular formula for it which I have given. This alcohol I call cerotine. If this substance be heated with lime and potash according to the method of Dumas, hydrogen gas is given off, and if the experiment be conducted with care there will hardly be traces of any other volatile product. In the tube is found an acid. The experiment requires considerable heat, and I have found that it is best made in a long combustion-tube, suspended by means of two corks in a large tube of porcelain, which forms an air-bath. The apparatus is heated by charcoal in a combustion-trough. In this manner the heat can be regulated with the greatest precision. The acid having been purified in the usual manner, which it is unnecessary again to refer to, is a substance highly crystalline in its texture and perfectly resembling in its sensible properties the cerotic acid from bees'wax, with which acid analysis shows it to be identical. The melting-point of this preparation was about a degree higher than that of the cerotic acid from wax, namely $81^{\delta} \mathrm{C}$.

$0.259 \mathrm{grm}$. gave $0.754 \mathrm{CO}_{2}$ and $0.309 \mathrm{HO}$, which correspond in 100 parts to-

$$
\begin{aligned}
& \text { Carbon . . . } 79 \cdot 39 \\
& \text { Hydrogen . . 13.28 } \\
& \text { Oxygen . } \cdot \frac{7 \cdot 33}{100 \cdot 00}
\end{aligned}
$$

This agrees with the formula $\mathrm{C}_{54} \mathrm{H}_{54} \mathrm{O}_{4}$.

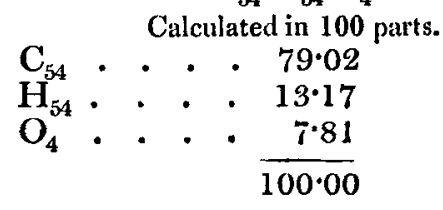


I prepared also the silver salt of this acid. The method used for its preparation was the same as that used in the case of the cerotic acid from bees'-wax.

I. $0.3775 \mathrm{grm}$. of this salt gave $0.862 . \mathrm{CO}_{2}$ and $0.349 \mathrm{HO}$.

II. $0.3625 \mathrm{grm}$. of this salt gave $0.833 \mathrm{CO}_{2}$ and 0.3385 $\mathrm{HO}$, which correspond in 100 parts to-

I.

Carbon . . 62.27

Hydrogen . . 10.27

Oxygen and silver $27 \cdot 46$
II. $62 \cdot 74$ 10.38 $26 \cdot 88$

$$
\overline{100 \cdot 00} \quad \overline{100 \cdot 00}
$$

I. $0.654 \mathrm{grm}$. of the same gave $0.135 \mathrm{grm}$. of silver. II. $0.629 \mathrm{grm}$. of the same gave $0.1305 \mathrm{grm}$. of silver.

These correspond in parts per cent. to-

$$
\text { Silver . . . } 20.64 \quad \text { I. } 20.74
$$

The formula of the silver salt of cerotic acid requires-

$$
\begin{aligned}
& \text { In } 100 \text { parts. } \\
& \mathrm{C}_{54} \text {. . . } 6266 \\
& \mathrm{H}_{53} \text {. . . . 10.55 } \\
& \mathrm{O}_{4} \text {. . . . } 6.19 \\
& \mathrm{Ag} \cdot \cdot \cdot \frac{20 \cdot 90}{100 \cdot 00}
\end{aligned}
$$

\section{Sulphate of the Oxide of Cerotyle.}

When cerotine is treated in the cold with concentrated sulphuric acid, it is only acted on by the acid partially and at the surface. If the action be increased by heat, a reddening of the mass and decomposition take place. If however the cerotine be taken in a state of fine granular division, as obtained by crystallization out of æther, and in this condition acted upon by the acid, all decomposition is avoided and a perfect combination takes place of the acid with the cerotine. The granular crystals are to be dried between blotting-paper, and then digested with the sulphuric acid, in the cold, for two or three hours, sufficient acid being added to render the mixture a rather fluid paste. The mass is to be thrown into cold water, and washed out with the same on a filter. As long as the solution is acid the wash-water will go through perfectly clear, but when the acid is washed out it becomes slightly turbid. After the adhering acid has been thus removed, the substance may be dried in vacuo, and, when perfectly dry, dissolved in æther and crystallized out of that fluid. In this condition it is perfectly soluble even in water, and dissolves with the great- 
est facility in water to which the smallest quantity of alcohol has been added. When the solution in water has been evaporated to dryness at a low temperature, it remains in the form of a soft wax. HO.

I. $0.333 \mathrm{grm}$. of this substance gave $0.912 \mathrm{CO}_{2}$, and 0.3915

II. $0.3317 \mathrm{grm}$. of this substance gave $0.9025 \mathrm{CO}_{2}$ and $0.3865 \mathrm{HO}$, corresponding in 100 parts to-

I.

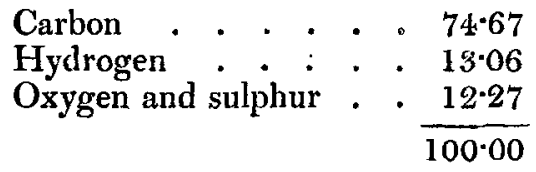

II.

$74 \cdot 20$

$12 \cdot 95$

$12 \cdot 85$

Owing to the loss of a portion of the substance I was not able to make a separate determination of the sulphur. These numbers, however, so correspond to the formula $\mathrm{SO}_{3}, \mathrm{C}_{54} \mathrm{H}_{55}$ $\mathrm{O}+\mathrm{HO}$, and so exclude all other probable formulæ, as to determine the constitution of the compound.

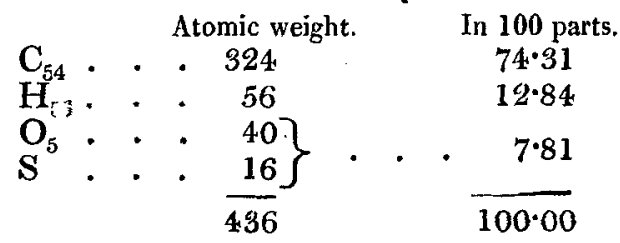

Adopting therefore the usual chemical language as to such compounds, this substance is to be regarded as the sulphate of the oxide of cerotyle, containing one equivalent of water, cerotyle being $\mathrm{C}_{54} \mathrm{H}_{55}$, the hypothetical radical of the alcohol.

\section{Chlor-cerotic Aldehyde-iChlor-cerotal.}

The action of chlorine on cerotine gives us a proof of the strong analogy of chemical constitution between alcohol and that substance, notwithstanding the wide interval by which they are separated in the alcoholic series. A body is formed analogous to chloral; two equivalents of hydrogen are removed without substitution, the substance passing, apparently, through the condition of an aldehyde, before chlorine is substituted. The chlorine produces a similar change in the appearance of the substance to that which is produced by the action of chlojine on cerotic acid. The character of wax is entirely lost, and the substance converted into a perfectly transparent slightly yellow body, possessing the appearance and consistency of a gum-resin, and which becomes highly electric by friction. The experiment was made by passing the chlorine 
over the substance kept melted in a flask by means of a waterbath. The gas was dried. The action is slow, and the experiment takes several days. When no more action was perceived, the substance was boiled with water, dried in a waterbath, and analysed.

I. $0.394 \mathrm{grm}$. of the substance gave $0.5435 \mathrm{CO}_{2}$, and $0.169 \mathrm{HO}$.

II. $0.4404 \mathrm{grm}$. of the substance gave $0.6120 \mathrm{CO}_{2}$ and $0.186 \mathrm{HO}$, giving in 100 parts-

\begin{tabular}{|c|c|c|}
\hline $\begin{array}{l}\text { Carbon } \cdot \cdot \cdot \\
\text { Hydrogen } \\
\text { Oxygen and chlorine: }\end{array}$ & $\begin{array}{r}37 \cdot 62 \\
4 \cdot 77 \\
57 \cdot 61\end{array}$ & $\begin{array}{r}37 \cdot 89 \\
4 \cdot 70 \\
57 \cdot 41\end{array}$ \\
\hline & $100 \cdot 00$ & $100 \cdot 00$ \\
\hline
\end{tabular}

I. $0.51075 \mathrm{grm}$. of the substance gave $1 \cdot 141 \mathrm{grm}$. of chloride of silver, equivalent to 0.2814 chlorine.

II. $0.7035 \mathrm{grm}$. of the substance gave $1.574 \mathrm{grm}$. of chloride of silver, equivalent to 0.388 chlorine.

III. $0.667 \mathrm{grm}$. of the substance gave $1.489 \mathrm{grm}$. of chloride of silver, equivalent to 0.3673 chlorine, giving in 100 parts-

$$
\begin{aligned}
& \text { I. II. III. } \\
& \text { Chlorine . . } 55 \cdot 11 \quad 55 \cdot 10 \quad 55 \cdot 07
\end{aligned}
$$

From these data we may calculate for the substance the formula $\mathrm{C}_{54}\left\{\begin{array}{l}\mathrm{Cl}_{13 \frac{1}{4}} \mathrm{O}_{2} \\ \mathrm{H}_{40 \frac{3}{4}}\end{array}\right.$

Calculated in 100 parts-

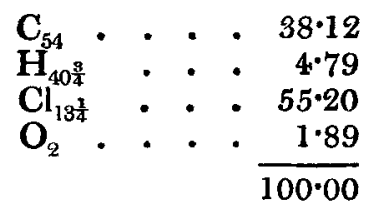

It is very difficult to tell with certainty when the action of the chlorine on the substance ceases, and I have therefore written the fractional equivalents, which agree rather more

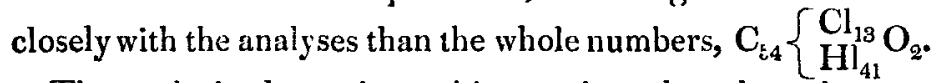

The analysis determines with certainty that the substance no longer belongs to the alcohol type; for the addition of two equivalents of hydrogen to the formula would require above 0.3 per cent. more hydrogen than the quantity found, a kind of error which is highly improbable. 
Cerotic Acid from the Saponification of the Wax.

The perfect washing out of the baryta salt from which the cerotine has to be separated, is attended with considerable difficulty. It is best effected by naphtha-alcohol or naphthaæther. The wax acid, after separation from the baryta salt, is to be purified, first by long boiling with water in an open vessel, to get rid of all traces of naphtha, and then by repeated crystallization out of æther. In this way the melting-point may be raised to $78^{\circ}, 79^{\circ} \mathrm{C}$. In appearance the acid perfectly resembles the cerotic acid, with which it has also the same melting-point. The substance, after long-repeated crystallizations, was analysed.

I. 0.2632 grm. gave $0.765 \mathrm{CO}_{2}$ and $0.3035 \mathrm{HO}$.

II. $0.2631 \mathrm{grm}$. gave $0.7626 \mathrm{CO}_{2}$ and $0.3095 \mathrm{HO}$.

III. $0.232 \mathrm{grm}$. gave $0.6695 \mathrm{CO}_{2}$ and $0.274 \mathrm{HO}$.

These analyses give in parts per cent.-

I. II. III.

Carbon . . 79.26 79.04 78.70

Hydrogen . $12.81 \quad 13.07 \quad 13.12$

Oxygen : $\frac{7.93}{100.00} \quad \frac{7.89}{100.00} \quad \frac{8.18}{100.00}$

The formula $\mathrm{C}_{54} \mathrm{H}_{54} \mathrm{O}_{4}$ requires-

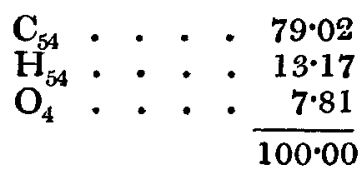

I prepared the silver salt of this acid.

I. $0.656 \mathrm{grm}$. of substance gave 0.1335 silver.

II. $0.6635 \mathrm{grm}$. of substance gave $0 \cdot 1355$ silver, which gives in 100 parts-

$$
\text { Silver . } \quad 20.35 \quad 20 \cdot 42
$$

I. $0.4675 \mathrm{grm}$. of the salt gave $1.072 \mathrm{CO}_{2}$ and $0.431 \mathrm{HO}$. II. 0.4655 grm. of the salt gave $1.0767 \mathrm{CO}_{2}$ and 0.4295 $\mathrm{HO}$, which give per cent.-

$$
\begin{aligned}
& \text { I. II. }
\end{aligned}
$$

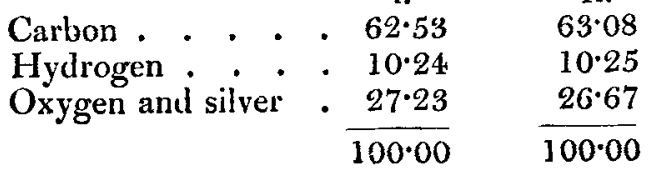


The formula $\mathrm{C}_{54} \mathrm{H}_{53} \mathrm{O}_{3}+\mathrm{AgO}$ requires-

$$
\begin{aligned}
& \mathrm{C}_{54} \text {. . . } 62 \cdot 66 \\
& \mathrm{H}_{53} \text {. . . } 10.25 \\
& \mathrm{O}_{4} \text {. . . . } 619 \\
& \mathrm{Ag} \cdot \cdot \quad \cdot \quad 20 \cdot 90
\end{aligned}
$$

There is a difference between the calculated and found amount of silver of about 0.5 per cent. which I cannot doubt arises from traces of cerotine still adhering to the acid, notwithstanding all the pains I took to wash out the salt : for I found that the amount of silver increased with the purification of the acid by crystallization, even after I could find not the slightest variation in the melting-point. The silver salt made from an acid which was a part of the same original preparation as the above and of exactly the same melting-point, but which had not been so often crystallized, gave in two determinations $20^{\circ} 07$ and $20^{\circ} 09$ per cent. silver. It will be seen that the formula I have given for the acid is confirmed by the analysis of the acid obtained from distillation of the wax.

\section{Distillation of Cerotine.}

Cerotine requires a high temperature for its distillation. The operation is accompanied with little explosions, owing to the formation of a small quantity of water. The distillate is perfectly colourless to the last, and solid, giving, when pressed with blotting-paper, hardly a trace of oil; it resembles in its general appearance the cerotine itself, but has a lower meltingpoint, about $70^{\circ} \mathrm{C}$.

The distillate also contains a larger per-centage of carbon than the substance. A portion, melting at $73^{\circ} \mathrm{C}$. and purified by crystallization, gave to analysis carbon 83.20 and hydrogen 14.22 per cent.; but it is very difficult to raise the meltingpoint much beyond $73^{\circ} \mathrm{C}$. At first, from the constancy of the melting-point, I was led to think that a new oxygen combination had been formed. I found, however, afterwards that the melting-point could be raised to $79^{\circ} \mathrm{C}$.; that is, the melting-point of the alcohol, a substance of a lower melting-point remaining behind; and there can be little doubt but that part of the cerotine distils over unaltered, while another portion decomposes into solid hydrocarbon and water. I found, in fact, that the amount of carbon diminished as the meltingpoint was raised. 


\section{Distillation of Chinese Wax.}

The Chinese wax is decomposed by heat. When distilled, the distillate consists of two portions; a wax acid which forms the earlier portions of the distillate, and a portion which is not acted on by potash, and from which the acid portion may be separated by saponification. The soap requires to be drawn off by a siphon. I will first give the analysis of the acid, which is undoubtedly the same acid as that procured by saponification of the wax itself. The melting-point of the acid may, by the methods pursued in other cases of separation from the soap, purification and crystallization out of æether, be raised to $80^{\circ}, 81^{\circ} \mathrm{C}$., which is probably the true meltingpoint of the cerotic acid.

$0.2613 \mathrm{grm}$. of the acid gave $0.7555 \mathrm{CO}_{2}$ and $0.3075 \mathrm{HO}$, which corresponds in parts per cent. to-

$$
\begin{aligned}
& \text { Carbon . . . } 78.85 \\
& \text { Hydrogen . . 13.08 } \\
& \text { Oxygen } \cdot \cdot \cdot \frac{8 \cdot 07}{100 \cdot 00}
\end{aligned}
$$

I give here again, for the sake of comparison, the numbers of the formula.

$$
\begin{aligned}
& \text { Calculated. } \\
& \mathrm{C}_{54} \text {. . . 79.02 } \\
& \mathbf{H}_{54} \text {. . . . } 13.17 \\
& \mathrm{O}_{4} \cdot . \cdot 781 \\
& \overline{100 \cdot 00}
\end{aligned}
$$

The siver salt of the acid, prepared as in other cases, gave to analysis the following results :-

$0.3625 \mathrm{grm}$. of the salt gave $0.827 \mathrm{CO}_{2}$ and $0.332 \mathrm{HO}$, giving in 100 parts, -

$$
\begin{aligned}
& \text { Carbon . . . . . 62.21 } \\
& \text { Hydrogen . . . . 10.18 } \\
& \text { Oxygen and silver . } \frac{27 \cdot 61}{100 \cdot 00}
\end{aligned}
$$

I. $0.649 \mathrm{grm}$. of the salt gave $0.139 \mathrm{grm}$. of silver.

II. $0.626 \mathrm{grm}$. of the same gave $0.13375 \mathrm{grm}$. of silver. These determinations correspond in parts per cent. to-

I.

Silver . . $21 \cdot 42 \quad 21 \cdot 19$

The formula $\mathrm{C}_{54} \mathrm{H}_{53} \mathrm{O}_{3}+\mathrm{AgO}$ requires- 


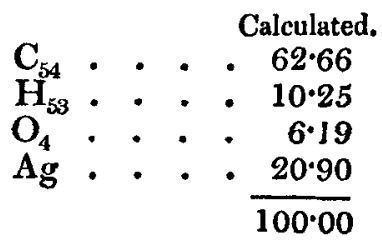

Cerotene.

The portion of the distillate from which the soap has been separated by decantation and by repeated washings and boiling out with water, consists chiefly of a solid hydrocarbon, one of those substances which have been comprehended and con. founded under the general name of paraffine. It is mixed with a certain quantity of oil, from which it may be almost entirely separated by pressure in a press between folds of blottingpaper. If this substance be crystallized out of naphtha-alcohol and then out of æether, it may be obtained of a melting-point of $57^{\circ}, 58^{\circ} \mathrm{C}$. In this state it is highly crystalline on cooling, and presents the general appearance of the substance called paraffine.

I. $0.2555 \mathrm{grm}$. gave $0.802 \mathrm{CO}_{2}$ and $0.331 \mathrm{HO}$.

II. $0.2593 \mathrm{grm}$. gave $0.810 \mathrm{CO}_{2}$ and $0.332 \mathrm{HO}$, which give in 100 parts,-

$$
\begin{aligned}
& \text { I. II. } \\
& \text { Carbon . . 85.60 } 85.20 \\
& \text { Hydrogen . . 14:39 } 14.23 \\
& \overline{99 \cdot 99} \quad \overline{99 \cdot 43}
\end{aligned}
$$

These analyses correspond to the formula

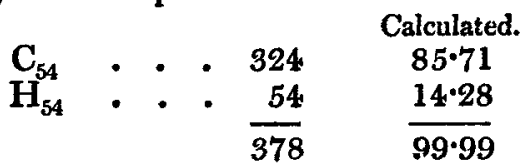

This substance may be called cerotene. After the discovery of the alcohol, there was a strong presumption that the hydrocarbon and the cerotine would be related in the manner expressed by the formula, the hydrocarbon being the olefiant gas of the wax alcohol. It was, however, very desirable to find some method for the determination of its formula. I investigated, with this view, the action of chlorine on the substance.

\section{Chlor-Ceratene.}

If moist chlorine be passed over the melted cerotene in the manner before described in the case of the other wax sab- 
stances, it is readily acted upon by the gas. It loses its wax character, becomes gum-like, and is ultimately converted into a transparent resin; the substance becoming harder and harder with the increase of the chlorine substituted, at length becoming extremely hard, and cracking in all directions, on cooling, on the surface of the glass on which it has been melted. The action goes on very slowly, but more rapidly with moist than with dry gas. It was continued for several weeks, until no more traces of hydrochloric acid formed could be observed.

During the operation portions of the substance were taken out at intervals and analysed.

$0.303 \mathrm{grm}$. of the first portion thus examined gave 0.3495 $\mathrm{CO}_{2}$ and $0.0965 \mathrm{HO}$, corresponding in 100 parts to-

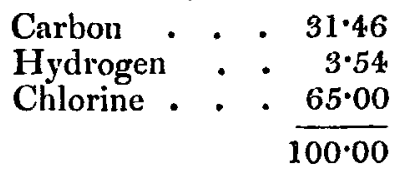

These numbers agree with the formula $\mathrm{C}_{54}\left\{\begin{array}{l}\mathrm{H}_{35} \\ \mathrm{Cl}_{19}\end{array}\right.$, which requires in 100 parts, -

$$
\begin{aligned}
& \mathrm{C}_{54} \text {. . . } .31 \cdot 31 \\
& \mathrm{H}_{35} \text {. . . . } 3.39 \\
& \mathrm{Cl}_{19} \cdot \cdot \frac{65 \cdot 30}{100 \cdot 00}
\end{aligned}
$$

After an interval of about four days the substance was again analysed.

I. $0.376 \mathrm{grm}$. of the substance gave $0.4060 \mathrm{CO}_{2}$ and 0.9085 HO.

II. $0.362 \mathrm{grm}$. of the substance gave $0.3915 \mathrm{CO}_{2}$ and $0.1005 \mathrm{HO}$.

These analyses give in 100 parts,-

I.

Carbon - . $\begin{array}{r}29 \cdot 45 \\ 0.91\end{array}$

Hydrogen . . 2.91

Chlorine $\cdot \frac{68.64}{100 \cdot 00}$

$100 \cdot 00$
II.

$29 \cdot 49$

3.09

$67 \cdot 42$

$100 \cdot 00$

The formula $\mathrm{C}_{54}\left\{\begin{array}{l}\mathrm{H}_{33} \\ \mathrm{Cl}_{21}\end{array}\right.$ requires

$$
\begin{aligned}
& \mathrm{C}_{54} \text {. . }{ }^{29 \cdot 43} \\
& \mathrm{H}_{33} \text {. . . . } 299 \\
& \mathrm{Cl}_{21} \text {. . . } 67.58 \\
& \overline{100 \cdot 00}
\end{aligned}
$$


After a further interval of several days the substance was again analysed. HO.

I. $0.4434 \mathrm{grm}$ of the substance gave $0.464 \mathrm{CO}_{2}$ and 0.115

II. $0.309 \mathrm{grm}$. of the substance gave $0.323 \mathrm{CO}_{2}$ and 0.08 $\mathrm{HO}$, which give in 100 parts, -

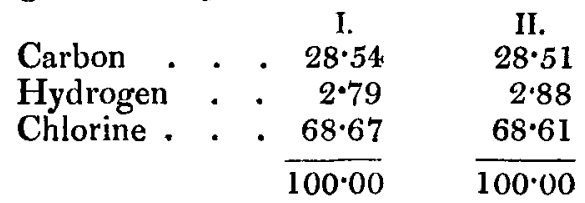

Notwithstanding that between these and the last analyses the action of the chlorine had been prolonged for a considerable time, the formula shows a difference of only one equivalent of chlorine.

$$
\begin{aligned}
& \text { The formula } \mathrm{C}_{54}\left\{\begin{array}{l}
\mathrm{H}_{32} \\
\mathrm{Cl}_{22}
\end{array}\right. \text { requires } \\
& \mathrm{C}_{54} \text {. . . } 28.76 \\
& \mathrm{H}_{32} \text {. . . . } 284 \\
& \mathrm{Cl}_{22} \text {. . . } 68.40 \\
& \overline{100 \cdot 00}
\end{aligned}
$$

These analyses determine with certainty the ratio of the hydrogen to the carbon in the cerotene, and leave no doubt as to the nature of the hydrocarbon. M. Lewy attempted to take the density of the vapour of paraffine from bees'-wax. He found, however, that this could not be effected, as the substance was altered, in process of conversion into vapour, with the formation of a small quantity of hydrocarbon gas; the paraffine however remaining white, and the analysis showing no variation in composition*. It has been also remarked by others that if bees'-wax be repeatedly distilled, the solid hydrocarbon disappears from the distillate. These observations point to the source of the oil in the distillation of the Chinese wax, viz. the transformation of the cerotene itself into isomeric hydrocarbons. In fact, I found, if the cerotene be distilled and redistilled in a closed tube of the form annexed, that by effecting the distillation in this manner under pressure, after about two distillations the distillate becomes liquid and the solid matter entirely disappears. The

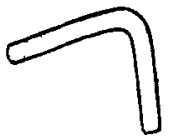
experiment after about six distillations was put an end to by the bursting of the heated end of the tube, when a large quantity of combustible vapour was given off. The oil which had * Ann. de Chimie, Series III. vol. v. p. 398. 
collected at the other end of the tube was a mixture of hydrocarbons of various boiling-points, from $75^{\circ} \mathrm{C}$. to above $260^{\circ} \mathrm{C}$. No trace of solid matter was to be seen.

If from the products of decomposition we turn to the analysis of the Chinese wax itself, we find numbers which are perfectly consistent with the idea that the chemical position of this body is among the class of compound æthers, where its reactions also would lead us to place it.

To purify the substance, it is to be crystallized out of naphtha and alcohol; washed with æther to remove the naphtha; boiled with water and crystallized again out of absolute alcohol, in which it is soluble, although with difficulty. Its melting-point is $82^{\circ} \mathrm{C}$.

I. 0.2644 grm. gave $0.798 \mathrm{CO}_{2}$ and $0.323 \mathrm{HO}$.

II. 0.2622 grm. gave $0.79 \mathrm{CO}_{2}$ and $0.3205 \mathrm{HO}$, which give in 100 parts-

$$
\begin{aligned}
& \text { Carbon . . 82.31 82.16 } \\
& \text { Hydrogen . . 13.57 13.58 } \\
& \text { Oxygen } \cdot \cdot \frac{4 \cdot 12}{100 \cdot 00} \quad \frac{4 \cdot 26}{100 \cdot 00}
\end{aligned}
$$

These numbers agree with the formula

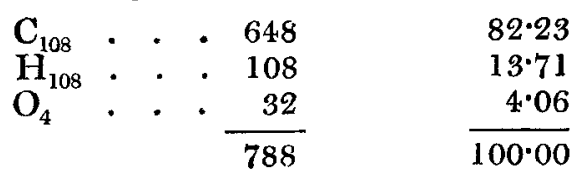

This formula affords us a simple solution of the decompositions of this substance by saponification and by heat.

In the former case,

$$
\mathrm{C}_{108} \mathrm{H}_{108} \mathrm{O}_{4}+\mathrm{KO}, \mathrm{HO}=\overbrace{\mathrm{C}_{54} \mathrm{H}_{53} \mathrm{O}_{3}, \mathrm{KO}}+\mathrm{C}_{54} \mathrm{H}_{56} \mathrm{O}_{2} \text {. }
$$

In the latter,

$$
\mathrm{C}_{108} \mathrm{H}_{108} \mathrm{O}_{4}=\mathrm{C}_{54} \mathrm{H}_{54} \mathrm{O}_{4}+\mathrm{C}_{54} \mathrm{H}_{54} \text {. }
$$

It is my intention shortly to offer to the Society another communication, on the nature of myricine from bees'-wax ; but I will now take the opportunity of stating that I have discovered in the investigation two wax substances of the formulæ $\mathrm{C}_{60} \mathrm{H}_{62} \mathrm{O}_{2}$ and $\mathrm{C}_{92} \mathrm{H}_{92} \mathrm{O}_{4}$. 